Article

\title{
Electrostatic-Interaction-Driven Assembly of Binary Hybrids towards Fire-Safe Epoxy Resin Nanocomposites
}

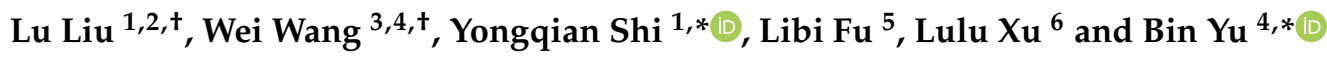 \\ 1 College of Environment and Resources, Fuzhou University, 2 Xueyuan Road, Fuzhou 350116, China; \\ lyqian@mail.ustc.edu.cn \\ 2 Hefei Institute for Public Safety Research, Tsinghua University, 5999 Xiyou Road, Hefei, Anhui 230026, China \\ 3 State Key Laboratory of Fire Science, University of Science and Technology of China, 96 Jinzhai Road, \\ Anhui 230026, China; wwei433@mail.ustc.edu \\ 4 Department of Architecture and Civil Engineering, City University of Hong Kong, Tat Chee Avenue, \\ Kowloon 999077, Hong Kong \\ 5 College of Civil Engineering, Fuzhou University, 2 Xueyuan Road, Fuzhou 350116, China; fulibi@fzu.edu.cn \\ 6 School of Materials Science \& Engineering, Nanyang Technological University, Singapore 639798, Singapore; \\ lulu.xu@ntu.edu.sg \\ * Correspondence: shiyq1986@fzu.edu.cn (Y.S.); yubin2-c@my.cityu.edu.hk (B.Y.); \\ Tel.: +86-591-22866082 (Y.S.); +852-65291052 (B.Y.) \\ + These authors contributed equally to this work (co-first author)
}

Received: 25 December 2018; Accepted: 27 January 2019; Published: 1 February 2019

check for updates

\begin{abstract}
Manganese dioxide $\left(\mathrm{MnO}_{2}\right)$, as a promising green material, has recently attracted considerable attention of researchers from various fields. In this work, a facile method was introduced to prepare binary hybrids by fabricating three-dimensional (3D) zinc hydroxystannate (ZHS) cubes on two-dimensional (2D) $\mathrm{MnO}_{2}$ nanosheets towards excellent flame retardancy and toxic effluent elimination of epoxy (EP) resin. Microstructural analysis confirmed that the morphologies and structures of $\mathrm{MnO}_{2} @ \mathrm{ZHS}$ binary hybrids were well characterized, implying the successful synthesis. Additionally, the morphological characterization indicated that $\mathrm{MnO}_{2} @ \mathrm{ZHS}$ binary hybrids could achieve satisfactory interfacial interaction with the EP matrix and be well dispersed in nanocomposites. Cone calorimeter test suggested that $\mathrm{MnO}_{2} @ \mathrm{ZHS}$ binary hybrids effectively suppressed the peak of heat release rate and total heat release of EP nanocomposites, performing better than $\mathrm{MnO}_{2}$ or ZHS alone. Condensed-phase analysis revealed that $\mathrm{MnO}_{2} @ \mathrm{ZHS}$ binary hybrids could promote the char density and graphitization degree of char residues and thereby successfully retard the permeation of oxygen and flammable gases. Moreover, through the analysis of gas phase, it can be concluded that $\mathrm{MnO}_{2} @ Z \mathrm{ZHS}$ binary hybrids could efficiently suppress the production of toxic gases during the degradation of EP nanocomposites. This work implies that the construction of 2D/3D binary hybrids with an interfacial interaction is an effective way to fabricate high-performance flame retardants for EP.
\end{abstract}

Keywords: binary hybrids; manganese dioxide; zinc hydroxystannate; flame retardancy; epoxy resin

\section{Introduction}

Epoxy resin (EP), one of the most important thermosetting polymers, has been widely used in the fields of furniture coatings [1], circuit boarding [2], aeronautical material [3], and so forth [4-6] in virtue of its excellent mechanical properties, outstanding optical property, glorious resistance to solvent and chemical corrosion, and high climate resistance. However, analogous to most other 
polymers, EP resin can be easily ignited and sharply spread, accompanied with large amounts of smoke and heat release. It is well known that smoke and toxic gases are the main reasons for death in fire accidents. Hence, to meet fire safety regulations and expand the use of EP in the fields that require flame resistance, a significant number of flame-retardant techniques for EP resins are developed. Some kinds of flame retardants have been gradually forbidden in most countries, due to toxic gases, such as hydrogen cyanide, contained in the pyrolysis products during the combustion process $[7,8]$. For instance, the most used brominated flame retardants often result in the formation of notorious pollutants, most notably, brominated and mixed halogenated dioxins $[9,10]$. Therefore, how to prepare green and effective flame retardants for EP remains a global topic for researchers.

In recent years, the nanoscale fillers, such as inorganic materials, have attracted considerable attention to impart polymers with excellent mechanical properties, antibacterial properties, flame retardancy, and so forth [11-16]. Generally, inorganic materials can endow polymers with excellent flame retardancy at a low loading. Moreover, different from other organic flame retardants, the incorporation of inorganic materials with a low addition will not deteriorate the mechanical properties of polymer materials. Inorganic materials with different morphologies and element composition show total flame retardancy mechanism towards a variety of polymers. Usually, one-dimensional inorganic materials, such as carbon nanotubes, $\mathrm{FeOOH}$, and titanium dioxides [17-21], could form networks during the degradation process of the polymer matrix, which can play the function of physical barrier retarding the permeation of heat, oxygen, and pyrolysis products. Two-dimensional (2D) materials, including graphene, layered double hydroxides, molybdenum disulfide, and manganese dioxide $\left(\mathrm{MnO}_{2}\right)$, are usually regarded as the most efficient in improving the flame retardancy of polymers in virtue of their large surface area [22-24], which can effectively delay the transfer of oxygen and toxic and flammable gases. For the three-dimensional materials, for instance, silica spheres, titanium dioxides spheres, and zinc hydroxystannate (ZHS) [25-27], these inorganic materials can also improve the flame retardancy of polymers; the catalytic charring effect and large inner specific surface area are the main reasons for the enhanced properties. It is reported that the Lewis acid catalyst forms an initial cation, promoting the Friedel-Crafts reaction, which can effectively build $\mathrm{C}-\mathrm{C}$ bonds with aromatic compounds, thereby improving the char density [28]. In the case of ZHS cubes, such as metal hydroxides, they have been regarded as affinity probes, which possess the Lewis acidity [29]. Therefore, ZHS cubes are usually used as an efficient flame retardant to promote the formation of char residue.

Up to date, the concept of multicomponent systems has been applied in a variety of fields, including environment, lithium batteries, water research, and materials. In the case of materials, multicomponent systems can be realized by different methods. Very recently, the layer-by-layer technique has been employed to improve the flame retardancy of polymers such as cotton, polyamides, and flexible polyurethane foam [30,31]. This technique is mainly driven by the forces from electrostatic interactions, hydrogen bond interactions, and covalence bonds. A wide variety of functional molecules can be incorporated within the layer-by-layer coating, including polyelectrolytes and inorganic materials, to impart the matrix with the desired properties.

In this work, a binary component consisting of $2 \mathrm{D} \mathrm{MnO}_{2}$ nanosheets and three-dimensional (3D) ZHS binary hybrids was synthesized by the self-assembly method to endow the EP matrix with flame retardancy and toxic suppression properties. In our previous works, $\mathrm{MnO}_{2}$ nanosheets were confirmed to have an excellent physical barrier effect during the degradation process in virtue of their two-dimensional structure [32,33]. Hence, fabrication of 2D/3D $\mathrm{MnO}_{2} @ \mathrm{ZHS}$ binary hybrids was anticipated to achieve excellent flame retardancy and toxic effluent elimination, and the corresponding flame retardancy mechanism was also explored. 


\section{Materials and Methods}

\subsection{Raw Materials}

All chemicals were of analytical grade and used as received without further purification. Zinc sulfate heptahydrate $\left(\mathrm{ZnSO}_{4} \cdot 7 \mathrm{H}_{2} \mathrm{O}\right)$, sodium stannate trihydrate $\left(\mathrm{Na}_{2} \mathrm{SnO}_{3} \cdot 3 \mathrm{H}_{2} \mathrm{O}\right)$, and potassium permanganate $\left(\mathrm{KMnO}_{4}\right)$ were supplied by Sinopharm Chemical Reagent Co. Ltd. (Shanghai, China). Bisphenol-A type EP was purchased from Shixian Chemical Industry Co., Ltd. A curing agent (diaminodiphenylmethane) and sodium hydroxide were purchased from Sinopharm Chemical Reagent Co., Ltd.

\subsection{Synthesis of $\mathrm{MnO}_{2}$ Nanosheets and $\mathrm{ZHS}$ Cubes}

The synthesis process of $\mathrm{MnO}_{2}$ was according to the reported work [34]. In a typical process, $15 \mathrm{mmol}$ of $\mathrm{KMnO}_{4}$ was completely dissolved in $750 \mathrm{~mL}$ of deionized water. Then, $200 \mathrm{~mL}$ of ethyl acetate was added into the above solution by constantly stirring. The solution was maintained at $95^{\circ} \mathrm{C}$ and refluxed overnight. The obtained brown product was filtrated and washed with deionized water and ethanol consecutively, then dried at $80{ }^{\circ} \mathrm{C}$ for further use. In the case of ZHS cubes [25], $10 \mathrm{mmol}$ of $\mathrm{ZnSO}_{4} \cdot 7 \mathrm{H}_{2} \mathrm{O}$ was dissolved in $300 \mathrm{~mL}$ of deionized water at $25^{\circ} \mathrm{C}$. Once completely dissolved, the equal loading of $\mathrm{Na}_{2} \mathrm{SnO}_{3} \cdot \mathrm{H}_{2} \mathrm{O}$ was added into the above solution. The continuous stirring was maintained for $4 \mathrm{~h}$, and the white suspension was centrifuged and washed with deionized water several times and then dried at $60^{\circ} \mathrm{C}$ overnight.

\subsubsection{Preparation of $\mathrm{MnO}_{2} @ \mathrm{ZHS}$ Binary Hybrid}

$\mathrm{MnO}_{2} @ \mathrm{ZHS}$ binary hybrid was prepared by a simple electrostatic adsorption method. $\mathrm{MnO}_{2}(1 \mathrm{~g})$ was dispersed in $500 \mathrm{~mL}$ of deionized water with ultrasound-assisted mechanical agitation for $2 \mathrm{~h}$. On the other hand, $0.2 \mathrm{~g}$ of ZHS was dispersed in $300 \mathrm{~mL}$ of deionized water under ultrasonic and mechanical stirring for $1 \mathrm{~h}$. The $\mathrm{pH}$ value of ZHS suspension was adjusted to 5 by $0.1 \mathrm{M} \mathrm{HCl}$ solution and stirred for another $1 \mathrm{~h}$. Subsequently, the ZHS suspension was dropwise added into the $\mathrm{MnO}_{2}$ suspension within $30 \mathrm{~h}$ by constant mechanical stirring. Finally, the mixed suspension was stirred and maintained for $4 \mathrm{~h}$. The resultant was selected by centrifugation, washed by deionized water and dried at $80^{\circ} \mathrm{C}$ overnight.

\subsubsection{Preparation of Pure EP and EP Nanocomposites}

The preparation of EP nanocomposites was in accordance with our previous works [18]. Typically, $1.22 \mathrm{~g}$ of $\mathrm{MnO}_{2} @ \mathrm{ZHS}$ binary hybrid was added into $50 \mathrm{~mL}$ of acetone under ultrasonically assisted stirring to form a homogeneous suspension. Then, $50 \mathrm{~g}$ of premelted EP was poured into the above suspension under mechanical stirring and maintained over $6 \mathrm{~h}$. Subsequently, the suspension was maintained at $100{ }^{\circ} \mathrm{C}$ for $12 \mathrm{~h}$ to remove the solvent. Thereafter, $10 \mathrm{~g}$ of premelted 4,4'-diaminodiphenylmethane was injected into the mixture under constant stirring. Finally, EP nanocomposites could be obtained after being cured at $100^{\circ} \mathrm{C}$ for $2 \mathrm{~h}$ and $150{ }^{\circ} \mathrm{C}$ for $2 \mathrm{~h}$, respectively. The sample was marked as EP/ $\mathrm{MnO}_{2} @ \mathrm{ZHS} 2 \%$, and the others were fabricated by using the same strategy. The preparation process is illustrated in Figure 1. 


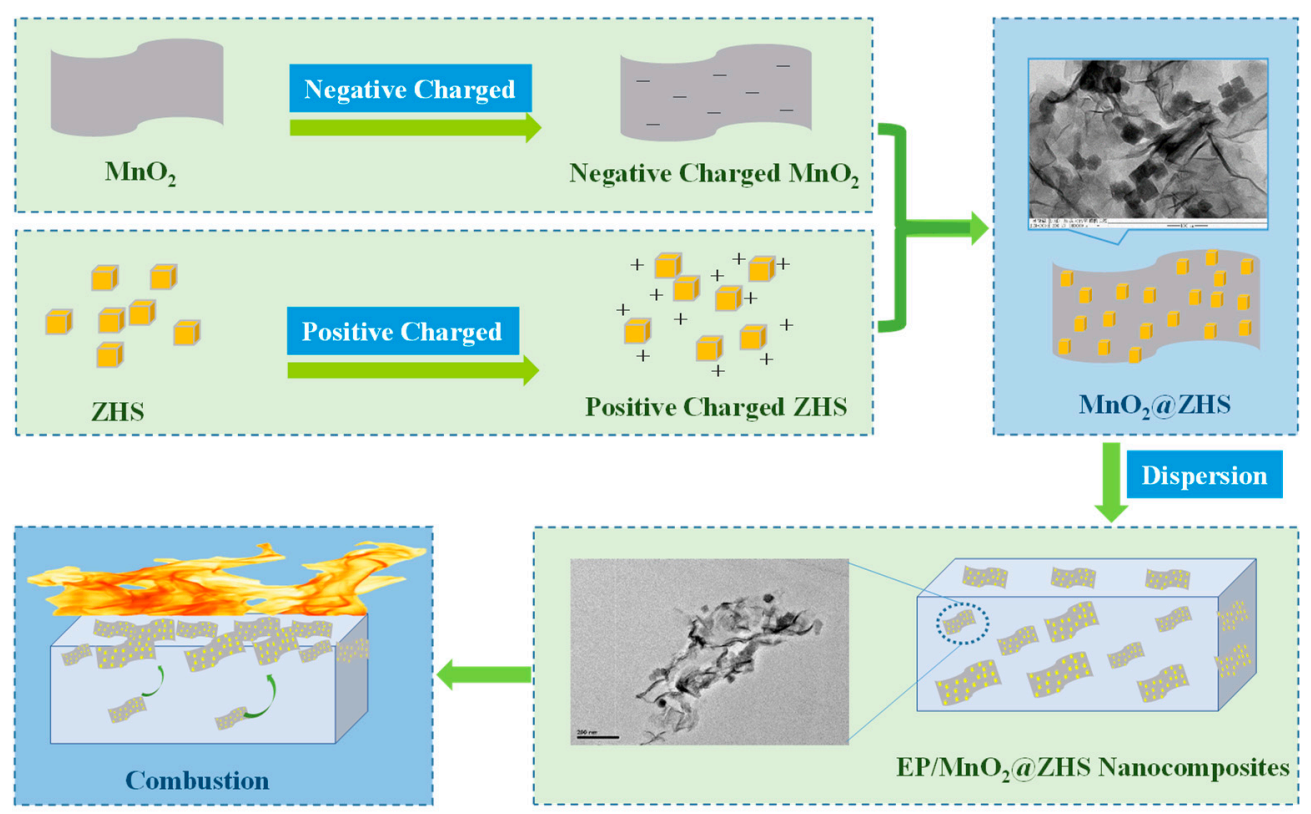

Figure 1. Synthesis of $\mathrm{MnO}_{2} @ \mathrm{ZHS}$ hybrids and flame retardancy mechanism in epoxy.

\subsection{Characterization}

X-ray diffraction (XRD) measurements were performed using a Japan Rigaku D = Max-Ra rotating anode X-ray diffractometer (RIGAKU, Tokyo, Japan) equipped with a $\mathrm{Cu}-\mathrm{Ka}$ tube and Ni filter $(\mathrm{k}=0.1542 \mathrm{~nm})$. Transmission electron microscopy (TEM) images were obtained using a JEOL JEM-100SX transmission electron microscope (JEOL, Tokyo, Japan) with an acceleration voltage of $100 \mathrm{kV}$. Thermogravimetric analysis (TGA) of as-prepared samples was undertaken using TGA-Q5000 apparatus (TA Co., New Castle, DE, USA) from 50 to $700{ }^{\circ} \mathrm{C}$ at a heating rate of $20^{\circ} \mathrm{C} \mathrm{min}-1$. The weight of all samples was maintained within 3-5 mg in an open platinum pan. The morphologies of $\mathrm{MnO}_{2}$ materials with three different dimensions, coated with a gold layer in advance, were observed using scanning electron microscopy (SEM; AMRAY1000B, Beijing R\&D Center of the Chinese Academy of Sciences, Beijing, China). TG-IR of the samples was performed using a TGA Q5000IR thermal gravimetric analyzer (TA Co., New Castle, DE, USA) that was interfaced to the Nicolet 6700 FTIR spectrophotometer (Thermo Scientific, Waltham, MA, USA). Approximately $5.0 \mathrm{mg}$ of the sample was placed in an alumina crucible and heated from 30 to $800{ }^{\circ} \mathrm{C}$ at a heating rate of $20^{\circ} \mathrm{C} \mathrm{min}^{-1}$ (helium atmosphere, flow rate of $45 \mathrm{~mL} \mathrm{~min}^{-1}$ ). A combustion test was performed on the cone calorimeter (Fire Testing Technology, Derby, UK) according to ISO 5660 standard, using specimens with size of $100 \times 100 \times 3 \mathrm{~mm}^{3}$. Each specimen was exposed horizontally to an external heat flux of $35 \mathrm{~kW}$ $\mathrm{m}^{-2}$. X-ray photoelectron spectroscopy (XPS) was performed on a VG Escalab Mark II spectrometer (Thermo-VG Scientific Ltd., West Sussex, UK), using Al K $\alpha$ excitation radiation ( $\mathrm{hv}=1486.6 \mathrm{eV}$ ).

\section{Results and Discussion}

\subsection{Characterization of $\mathrm{MnO}_{2} @ \mathrm{ZHS}$ Binary Hybrid}

TEM technique was employed to observe the morphologies of the $\mathrm{MnO}_{2}$ nanosheets and the $\mathrm{MnO}_{2} @ \mathrm{ZHS}$ binary hybrid, and the morphologies of the $\mathrm{MnO}_{2}$ nanosheets and their hybrid are presented in Figure 2. As can be observed in Figure 2a, the $\mathrm{MnO}_{2}$ nanosheets show layered structure with large surface area, and the wrinkle belonging to the layers can be obviously observed. After the assembly procedure forced by electrostatic adsorption, ZHS cubes are successfully fabricated on the surface of $\mathrm{MnO}_{2}$. As is shown in Figure $2 \mathrm{~b}-\mathrm{d}$, the $\mathrm{ZHS}$ cubes are firmly absorbed on the layers, and no ZHS cubes exist in the area beside the $\mathrm{MnO}_{2}$ nanosheets, indicating that there exist very strong 
electrostatic forces between the ZHS cubes and the $\mathrm{MnO}_{2}$ nanosheets. Moreover, the EDS spectrum of the $\mathrm{MnO}_{2} @ Z \mathrm{ZHS}$ binary hybrid is presented in Figure 3. The EDS profile confirms the presence of corresponding elements such as $\mathrm{Zn}, \mathrm{Sn}, \mathrm{Mn}$, and O. Figure 4 presents XRD patterns of the $\mathrm{MnO}_{2}$ nanosheets, ZHS cubes, and the $\mathrm{MnO}_{2} @ \mathrm{ZHS}$ binary hybrid. It is evident that the $\mathrm{MnO}_{2} @ \mathrm{ZHS}$ binary hybrid contains all the characteristic peaks of $\mathrm{MnO}_{2}$ and $\mathrm{ZHS}[35,36]$. These results indicate that the crystalline structures of $\mathrm{ZHS}$ and $\mathrm{MnO}_{2}$ have no changes during the absorption procedure. Moreover, TGA was used to measure the thermal stability of the $\mathrm{MnO}_{2} @ \mathrm{ZHS}$ binary hybrid and investigate the changes compared with that of the $\mathrm{MnO}_{2}$ nanosheets. Figure 5 shows the TGA curves of the $\mathrm{MnO}_{2}$ nanosheets and $\mathrm{MnO}_{2} @ \mathrm{ZHS}$ binary hybrid. The thermal stability of the $\mathrm{MnO}_{2} @ \mathrm{ZHS}$ binary hybrid is relatively lower than that of $\mathrm{MnO}_{2}$ nanosheets, due to the existence of predecomposition compared with $\mathrm{MnO}_{2}$. It is probably because of the separation of hydrate water from ZHS [37]. The further chemical state and element composition of $\mathrm{MnO}_{2}$ and $\mathrm{MnO}_{2} @ \mathrm{ZHS}$ were explored by XPS test.

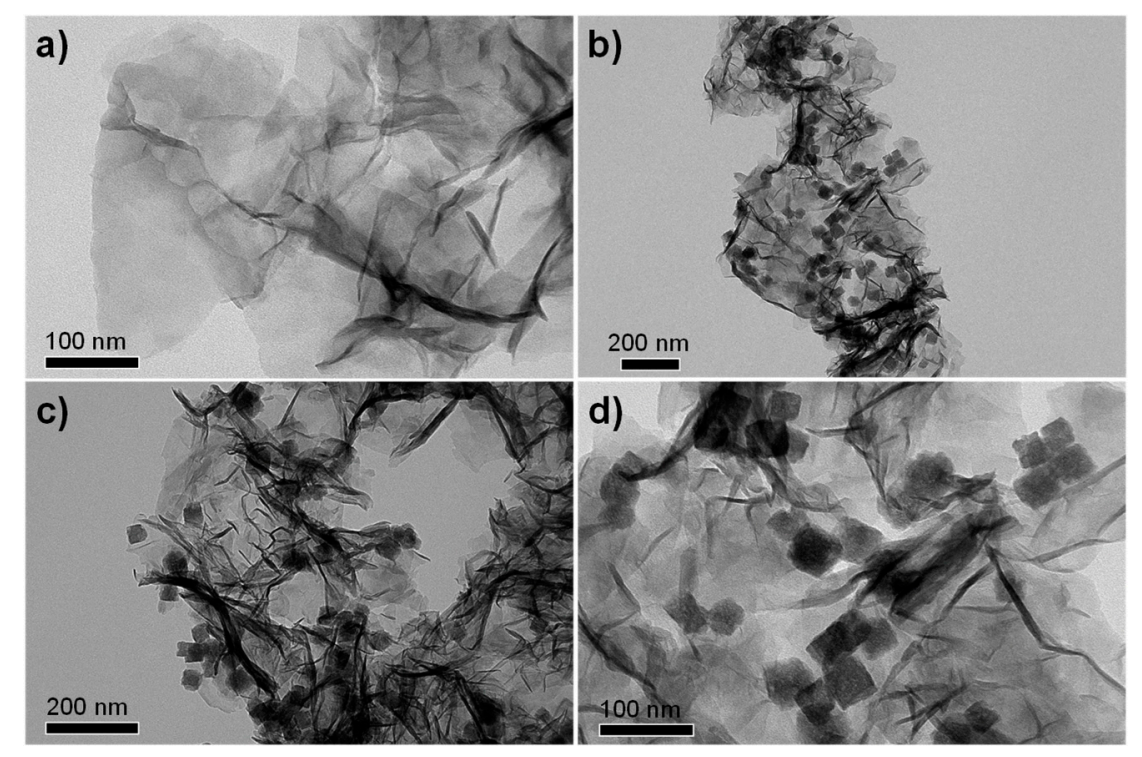

Figure 2. TEM images of (a) $\mathrm{MnO}_{2}$ nanosheets, and (b-d) $\mathrm{MnO}_{2} @ \mathrm{ZHS}$ hybrid.

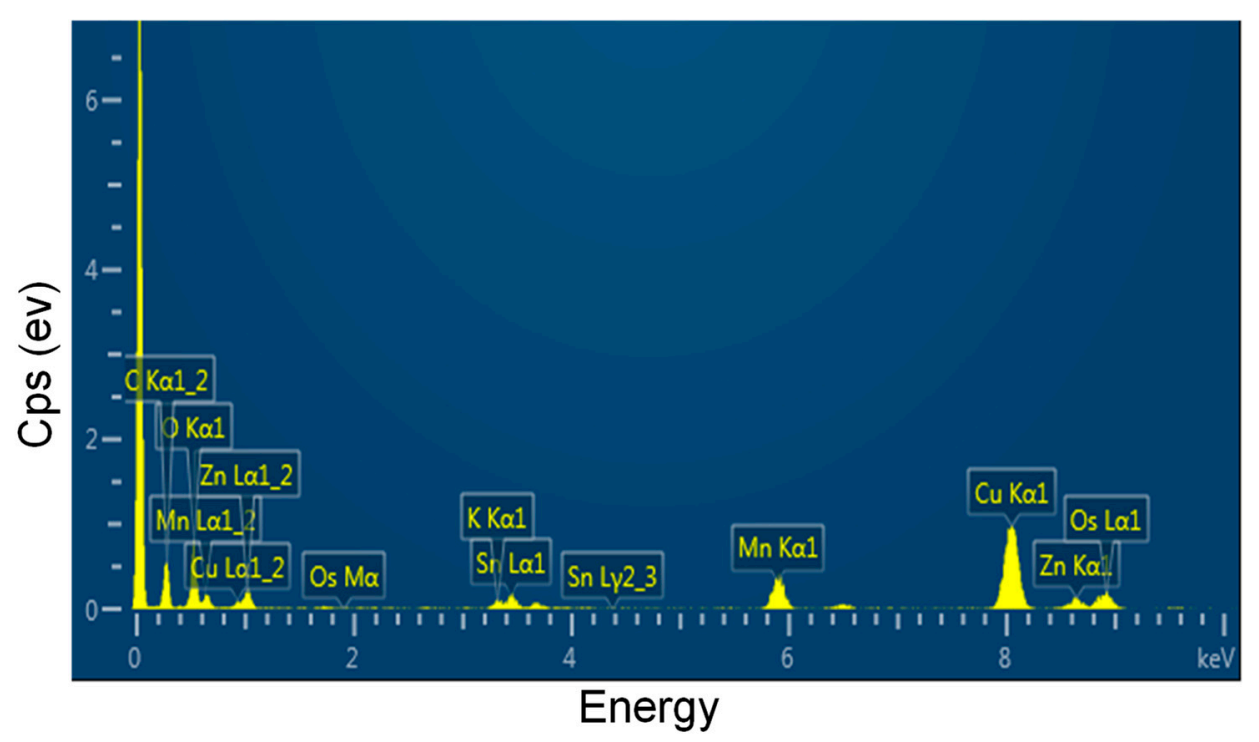

Figure 3. EDS profile of $\mathrm{MnO}_{2} @ \mathrm{ZHS}$. 


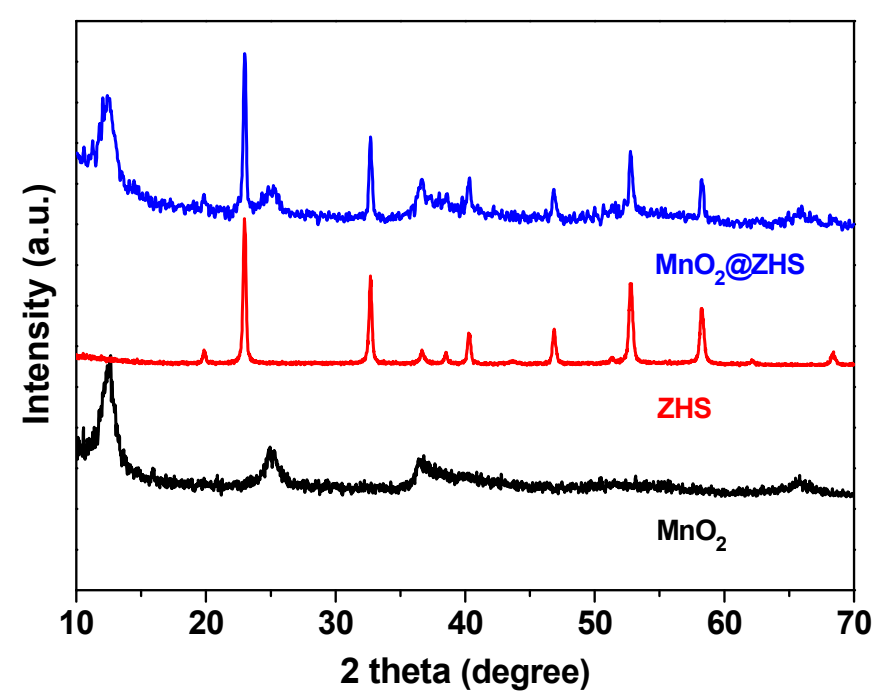

Figure 4. XRD patterns of $\mathrm{MnO}_{2}$, ZHS, and $\mathrm{MnO}_{2} @ \mathrm{ZHS}$ hybrid.

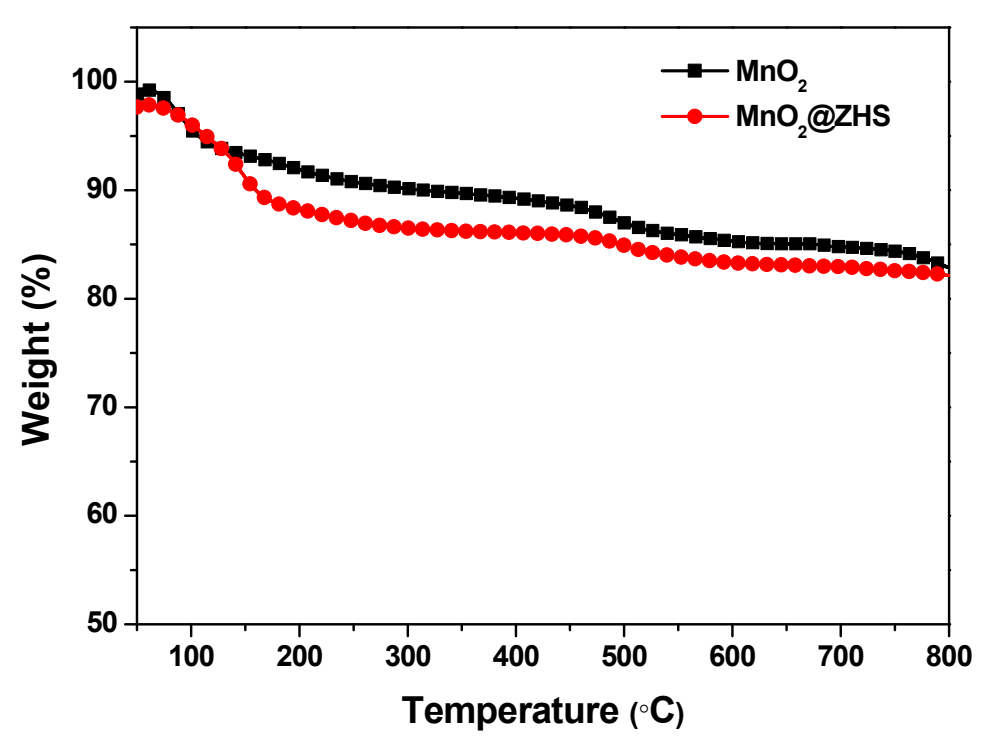

Figure 5. TGA curves of $\mathrm{MnO}_{2}$ and $\mathrm{MnO}_{2} @ \mathrm{ZHS}$.

In Figure 6a, the XPS survey spectra of $\mathrm{MnO}_{2}$ and $\mathrm{MnO}_{2} @ \mathrm{ZHS}$ are presented. The XPS survey spectra indicate that the $\mathrm{MnO}_{2} @ \mathrm{ZHS}$ hybrid is mainly comprised of $\mathrm{Mn}, \mathrm{O}, \mathrm{Sn}, \mathrm{Zn}, \mathrm{K}$, and C elements. The high-resolution $\mathrm{Zn} 2 \mathrm{p}^{3}$ and $\mathrm{Sn} 3 \mathrm{~d}$ are also shown in Figure $6 \mathrm{~b}$,c. The binding energies of $\mathrm{Zn} 2 \mathrm{p}^{3}$ and $\mathrm{Sn} 3 \mathrm{~d}$ are centered at 121.5 and $486.7 \mathrm{eV}$, respectively, which are attributed to $\mathrm{Zn}-\mathrm{O}$ and $\mathrm{Sn}-\mathrm{O}$ bonds [38]. Additionally, the high-resolution O1s spectra is exhibited in Figure 6d-f. The location at $529.8 \mathrm{eV}$ is ascribed to the $\mathrm{O}-\mathrm{Mn}-\mathrm{O}$ bond, and the peak centered at $531.2 \mathrm{eV}$ belongs to the $\mathrm{O}-\mathrm{Mn}-\mathrm{H}$ bond [39,40]. Additionally, it can be clearly found that the binding energy of $\mathrm{O} 1 \mathrm{~s}$ at around $532.3 \mathrm{eV}$ attributed to the weak bond (-OH) of the $\mathrm{MnO}_{2} @ \mathrm{ZHS}$ binary hybrid is higher than that of $\mathrm{MnO}_{2}$. This is reasonable due to the fabrication of ZHS, which is accompanied by abundant hydroxyl groups. 

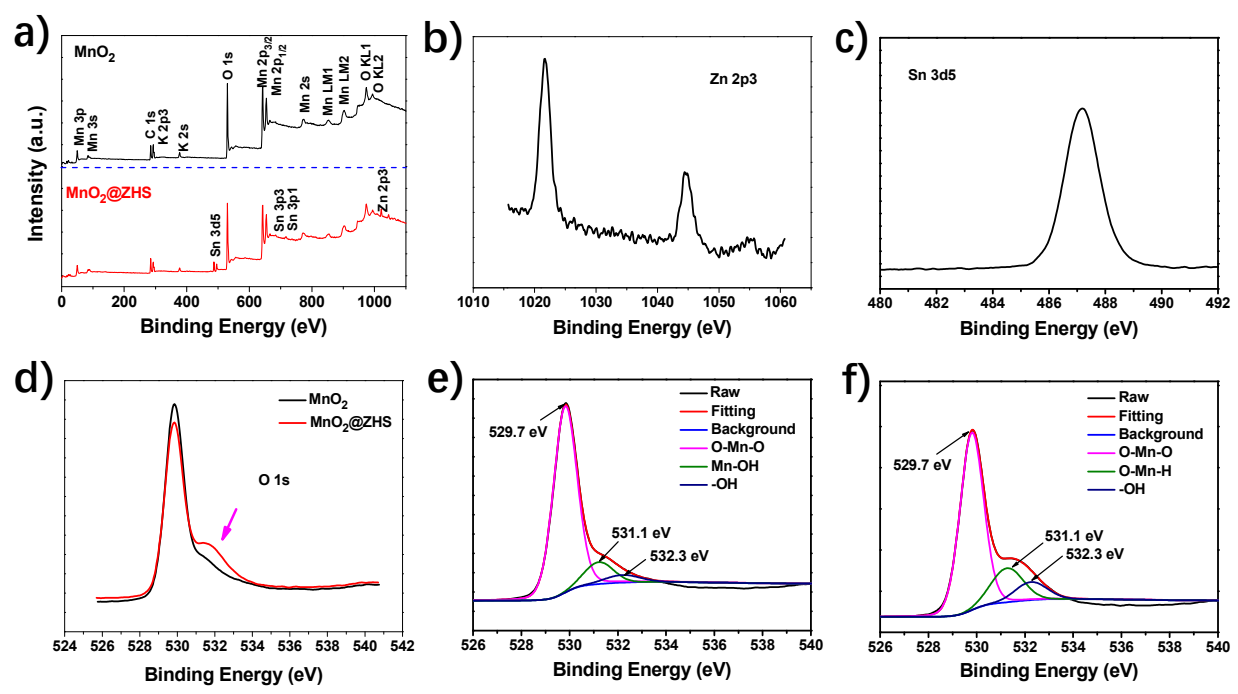

Figure 6. (a) XPS survey spectra of $\mathrm{MnO}_{2}$ and $\mathrm{MnO}_{2} @ \mathrm{ZHS}$ binary hybrid, (b) the high-resolution $\mathrm{Zn}$ 2p3, and (c) Sn 3d5 spectra of $\mathrm{MnO}_{2} @ Z \mathrm{ZHS}$ binary hybrid, (d) O1s spectra of $\mathrm{MnO}_{2}$ and $\mathrm{MnO}_{2} @ \mathrm{ZHS}$ binary hybrid, the deconvoluted O1s spectra of (e) $\mathrm{MnO}_{2}$ and (f) $\mathrm{MnO}_{2} @ \mathrm{ZHS}$ binary hybrid.

\subsection{Interfacial Adhesion Beween $\mathrm{MnO}_{2} @ Z H S$ Binary Hybrid and EP Matrix}

The morphology of the fracture surface of the samples is observed by SEM test, in order to further investigate the interfacial interaction between the nanofillers and EP matrix. As can be observed in Figure 7a, the fracture surface of pure EP shows smooth and clean. After the addition of $\mathrm{MnO}_{2}$ nanosheets, the surface of $\mathrm{EP} / \mathrm{MnO}_{2}$ with a $2 \mathrm{wt} \%$ loading appears rough and wrinkled, indicating the improved interfacial interaction between the $\mathrm{MnO}_{2}$ nanosheets and $\mathrm{EP}$ matrix (Figure $7 \mathrm{~b}$ ). In the case of EP/ $\mathrm{MnO}_{2} @ \mathrm{ZHS}$ with different loadings, the wrinkles on the surface show deeper than the addition of $\mathrm{MnO}_{2}$, declaring that the interfacial interactions between the $\mathrm{MnO}_{2} @ \mathrm{ZHS}$ binary hybrid and EP matrix are improved (Figure 7c-e). Moreover, as the loading of the $\mathrm{MnO}_{2} @ \mathrm{ZHS}$ binary hybrid increases, the fish-like folds become more delicate. EP/ $\mathrm{MnO}_{2} @ \mathrm{ZHS} 2 \%$ exhibits the most delicate surface among the samples, which is reasonably due to the increase of $\mathrm{MnO}_{2} @ \mathrm{ZHS}$ acting as stress points. Moreover, the EDS information of Figure 7e is listed in Figure 8, and the elements from the $\mathrm{MnO}_{2} @ Z H S$ binary hybrid can also be found. Therefore, the results obtained from SEM images demonstrate that the incorporation of $\mathrm{MnO}_{2} @ \mathrm{ZHS}$ can improve the interfacial interaction between $\mathrm{MnO}_{2} @ \mathrm{ZHS}$ and the EP matrix.

\subsection{Thermal Stabilities of Pure EP and Its Nanocomposites Studied by TGA Test}

The thermal stability of pure EP and EP nanocomposites is studied by TGA test, as shown in Figure 9. The onset decomposition temperature and the temperature at the maximal weight loss rate are denoted as $\mathrm{T}_{-10}$ and $\mathrm{T}_{\max }$, respectively. Pure EP and EP nanocomposites exhibit the same degradation process, showing a one-stage degradation process, which is ascribed to the decomposition of macromolecular chains. Additionally, it can be seen that after the incorporation of $\mathrm{MnO}_{2}$, the char residue of $\mathrm{EP} / \mathrm{MnO}_{2}$ at $800{ }^{\circ} \mathrm{C}$ increases compared with that of pure $\mathrm{EP}$, but the $\mathrm{T}_{-10 \%}$ and $\mathrm{T}_{\max }$ of $\mathrm{EP} / \mathrm{MnO}_{2}$ decrease, which is possibly attributed to the catalysis effect from $\mathrm{MnO}_{2}$ promoting the predecomposition of the matrix and the degradation of metal oxides. In the case of EP/ $\mathrm{MnO}_{2} @ \mathrm{ZHS}$ nanocomposites, the values of $\mathrm{T}_{-10 \%}$ and $\mathrm{T}_{\max }$ further decrease, which can be due to the predegradation of ZHS, thereby resulting in the predecomposition of the matrix. However, the increased residual content at $800{ }^{\circ} \mathrm{C}$ of $\mathrm{EP} / \mathrm{MnO}_{2} @ \mathrm{ZHS}$ nanocomposites is enhanced with the increase of the loading. Therefore, the addition of the $\mathrm{MnO}_{2} @ Z$ ZHS binary hybrid improves the char residue of the EP matrix. 


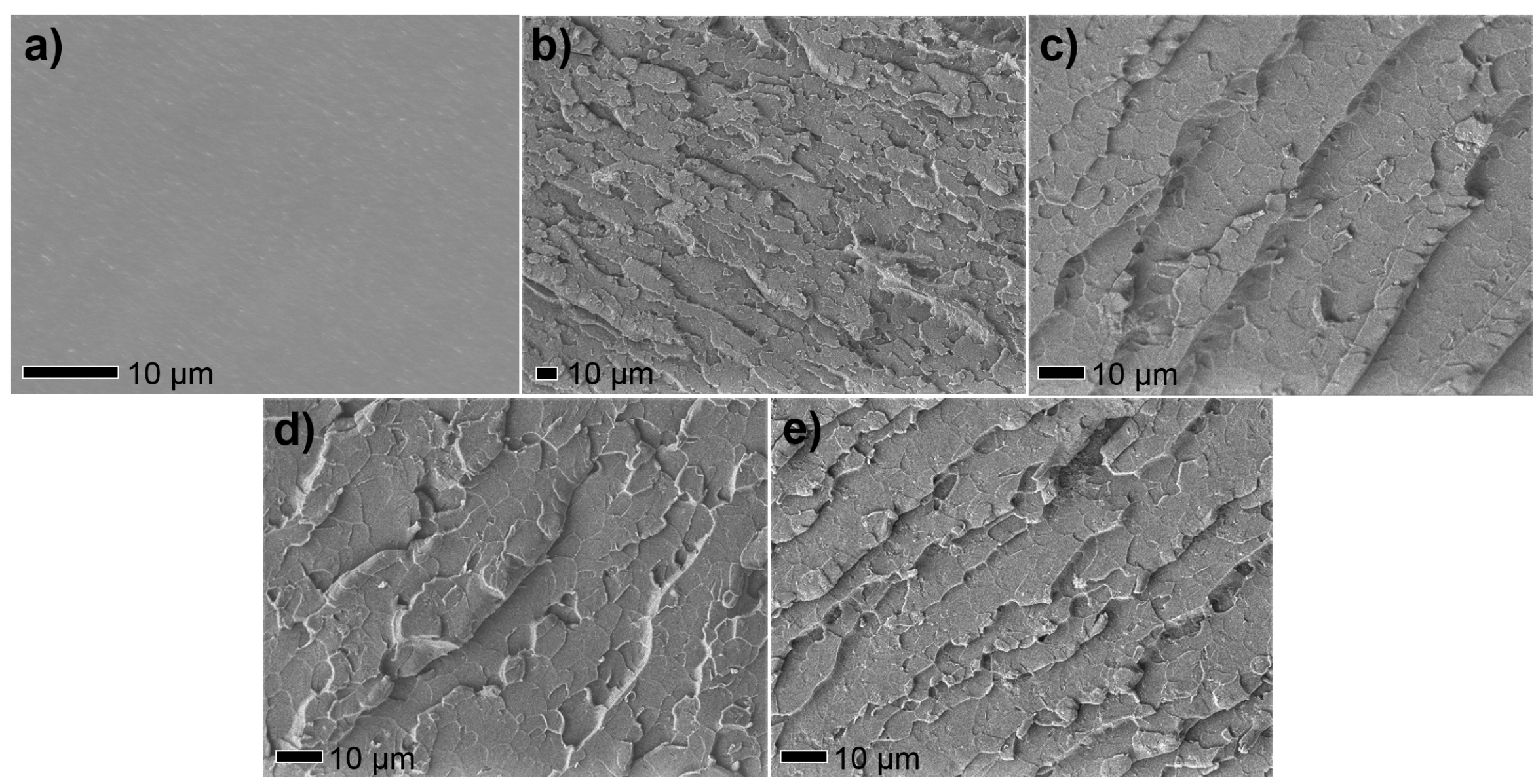

Figure 7. SEM images of fracture surfaces cryogenically broken after immersion in liquid nitrogen of (a) pure $\mathrm{EP},(\mathbf{b}) \mathrm{EP} / \mathrm{MnO}_{2} 2 \%,(\mathbf{c}) \mathrm{EP} / \mathrm{MnO}_{2} @ \mathrm{ZHS} 0.5 \%$, (d) $\mathrm{EP} / \mathrm{MnO}_{2} @ \mathrm{ZHS} 1 \%$, and e) $\mathrm{EP} / \mathrm{MnO}_{2} @ \mathrm{ZHS} 2 \%$. 


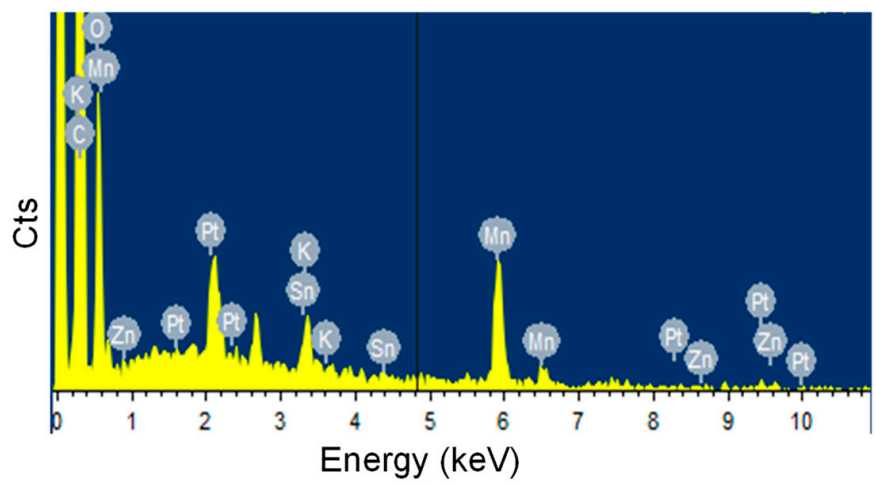

Figure 8. EDS profile of $\mathrm{EP} / \mathrm{MnO}_{2} @ \mathrm{ZHS} 2 \%$.
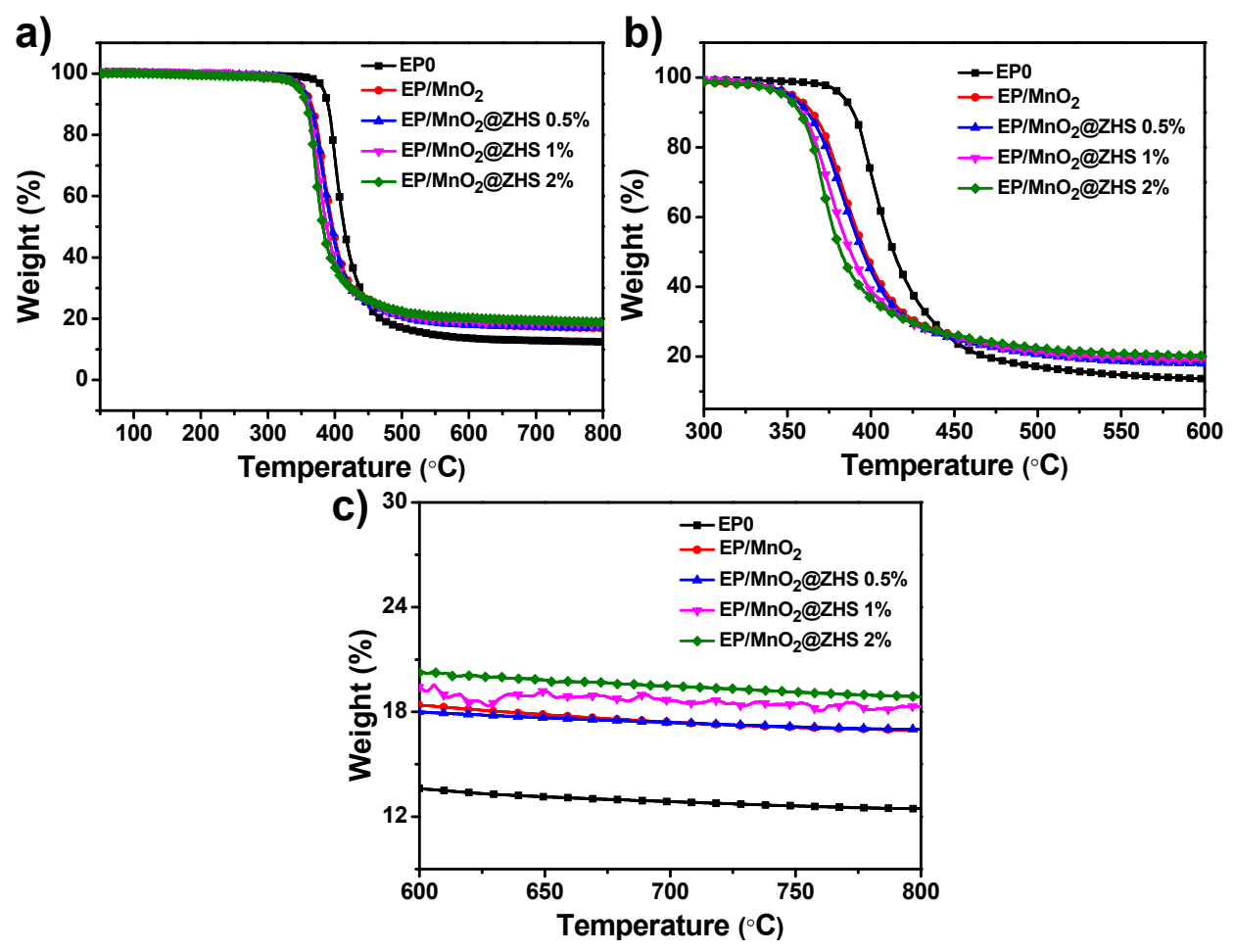

Figure 9. (a) TGA curve of pure EP and EP nanocomposites under nitrogen condition. (b,c) represent magnified TGA profiles of (a) at different temperatures.

\subsection{Flame Retardancy Evaluated by Cone Calorimeter}

The cone calorimeter is generally regarded as the most powerful tool to evaluate the force burning fire performance of materials through simulating a developing fire scenario on a fixed-sized specimen. The parameters, including peak heat release rate (PHRR) and total heat release (THR), are recognized as the crucial data for evaluating the fire safety of matrix. HRR and THR curves of pure EP and EP nanocomposites are presented in Figure 10. According to Figure 10a, incorporating $\mathrm{MnO}_{2}$ into the EP matrix can reduce the values of PHRR of EP nanocomposites, which is mainly attributed to the physical barrier effect. In the case of EP/ $\mathrm{MnO}_{2} @ Z \mathrm{ZHS}$ nanocomposites, all the values of PHRR are decreased as compared to that of pure EP. Moreover, as the amount of percent add-ons increases, the value of PHRR is further reduced. Thus, in terms of the decreased PHRR values, it can be indicated that the $\mathrm{MnO}_{2} @ Z H S$ hybrid shows the superior inhibition of heat release of the EP matrix. In addition, THR values of all EP nanocomposites shown in Figure 10b decrease obviously, in comparison with the pure one, showing that both $\mathrm{MnO}_{2}$ and the $\mathrm{MnO}_{2} @ Z$ ZHS binary hybrid can effectively suppress the 
heat release of EP nanocomposites during combustion. Moreover, the THR value of EP/ $\mathrm{MnO}_{2} @ \mathrm{ZHS}$ with a $2 \mathrm{wt} \%$ loading can achieve near $40 \%$ reduction, compared with the control $\mathrm{EP}$, which is rarely attained for the nanocomposites. The results of cone calorimetry illustrate that the function of charring formation of ZHS is successfully grafted on the $\mathrm{MnO}_{2}$ nanosheets. The catalytic charring function, combined with the physical barrier effect from the $\mathrm{MnO}_{2}$ nanosheets, can significantly enhance the flame retardancy of EP nanocomposites.
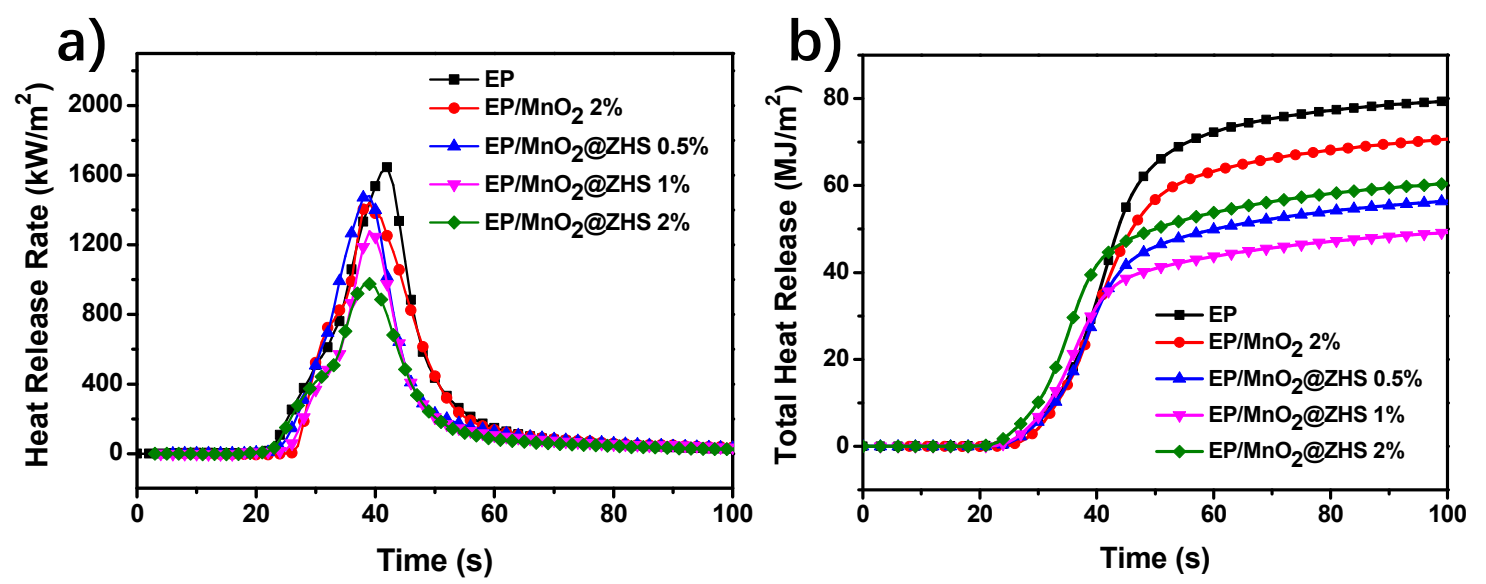

Figure 10. (a) HRR and (b) THR curves of pure EP and EP nanocomposites evaluated by cone calorimeter.

\subsection{Char Residues Analysis of EP and EP/MnO $@$ @HS Nanocomposites}

Digital photos of char residues of pure EP and EP nanocomposites are plotted in Figure 11, in order to directly observe their morphologies. As shown in Figure 11a, pure EP exhibits lower amount of char residues compared with other EP nanocomposites incorporated by $\mathrm{MnO}_{2} @ \mathrm{ZHS}$ binary hybrids. According to Figure 11d, the char residue of EP/ $\mathrm{MnO}_{2} @ \mathrm{ZHS} 2 \%$ shows a larger volume, illustrating a more effective catalytic charring formation by $\mathrm{MnO}_{2} @ \mathrm{ZHS}$. Additionally, the char residues of EP nanocomposites are covered by yellow-colored materials, which are the pyrolysis products obtained by the degradation of the $\mathrm{MnO}_{2} @ Z H S$ binary hybrids. Usually, for inorganic nanocomposites, the inorganic fillers would transfer to the surface of the matrix during the decomposition process. These yellow-colored degradation products can act as the insulation barrier, delaying the permeation of oxygen and flammable gases, thereby reducing the values of both PHRR and THR.

a)

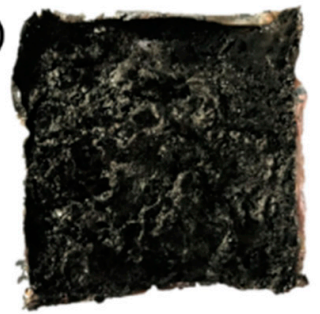

b)

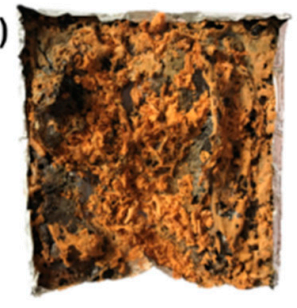

c)

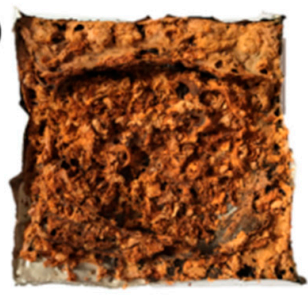

d)

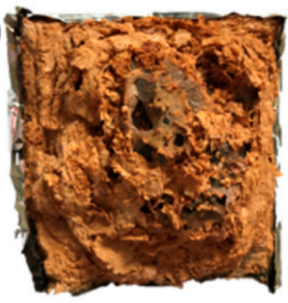

Figure 11. Digital images of char residues for (a) pure epoxy, (b) EP/ $\mathrm{MnO}_{2} @ \mathrm{ZHS} 0.5 \%$, (c) $\mathrm{EP} / \mathrm{MnO}_{2} @ \mathrm{ZHS} 1 \%$, (d) EP/MnO $2 @ \mathrm{ZHS} 2 \%$ after cone calorimeter tests. The scale of these samples is $100 \times 100 \mathrm{~mm}^{2}$.

To investigate the surface morphologies of char residues of pure EP and EP/ $\mathrm{MnO}_{2} @ \mathrm{ZHS}$, the char residues studied here were obtained after cone calorimetry and imaged via SEM test. According to the char residue of pure EP portrayed in Figure 12a, deep cracks and collapses are obviously observed and thereby lead the oxygen and flammable gases to transfer easily. After the incorporation of $\mathrm{MnO}_{2} @ \mathrm{ZHS}$ into the EP matrix, the char residue shows as more intact with less cracks (Figure 12b-d). 
Furthermore, as the loading increases up to $2 \mathrm{wt} \%$, the surface of EP/ $\mathrm{MnO}_{2} @ \mathrm{ZHS}$ is very smooth, and there are no collapses and cracks, which can perfectly retard the permeation of oxygen and toxic and flammable products. Overall, SEM images visually confirm that the addition of $\mathrm{MnO}_{2} @ \mathrm{ZHS}$ can significantly improve and perfect the char formation of EP nanocomposites. Besides, the Raman test was used to further study the inner graphitic structure of the char residues. As shown in Figure 12e-h, the Raman spectra of pure EP and EP nanocomposites all present two visible characteristic bands, namely, the D-band $\left(1353 \mathrm{~cm}^{-1}\right)$ and G-band $\left(1592 \mathrm{~cm}^{-1}\right)$, respectively attributed to the vibration of carbon atoms with dangling bonds in the plane terminations of disordered graphite or glass carbons and the vibration of $\mathrm{sp}^{2}$-bond carbon atoms in graphite layers. Generally, the ratio of the intensity of the D-band and G-band $\left(\mathrm{I}_{\mathrm{D}} / \mathrm{I}_{\mathrm{G}}\right)$ is used to evaluate the graphitization degree of char residues. It is well recognized that $\mathrm{sp}^{2}$-bond carbon atoms in graphite layers can behave as insulation barriers retarding the transfer of heat, oxygen, and flammable products. For the value of $\mathrm{I}_{\mathrm{D}} / \mathrm{I}_{\mathrm{G}}$, the lower value means the better graphitic structure and physical insulation [41]. With the incorporation of $\mathrm{MnO}_{2} @ \mathrm{ZHS}$ in the $\mathrm{EP}$ matrix, the value of $\mathrm{I}_{\mathrm{D}} / \mathrm{I}_{\mathrm{G}}$ gradually becomes lower. As the loading increases, $\mathrm{EP} / \mathrm{MnO}_{2} @ \mathrm{ZHS} 2 \%$ exhibits the lowest value of $\mathrm{I}_{\mathrm{D}} / \mathrm{I}_{\mathrm{G}}$, compared with the others, indicating the most intact char structure. These results are in good agreement with the SEM results.
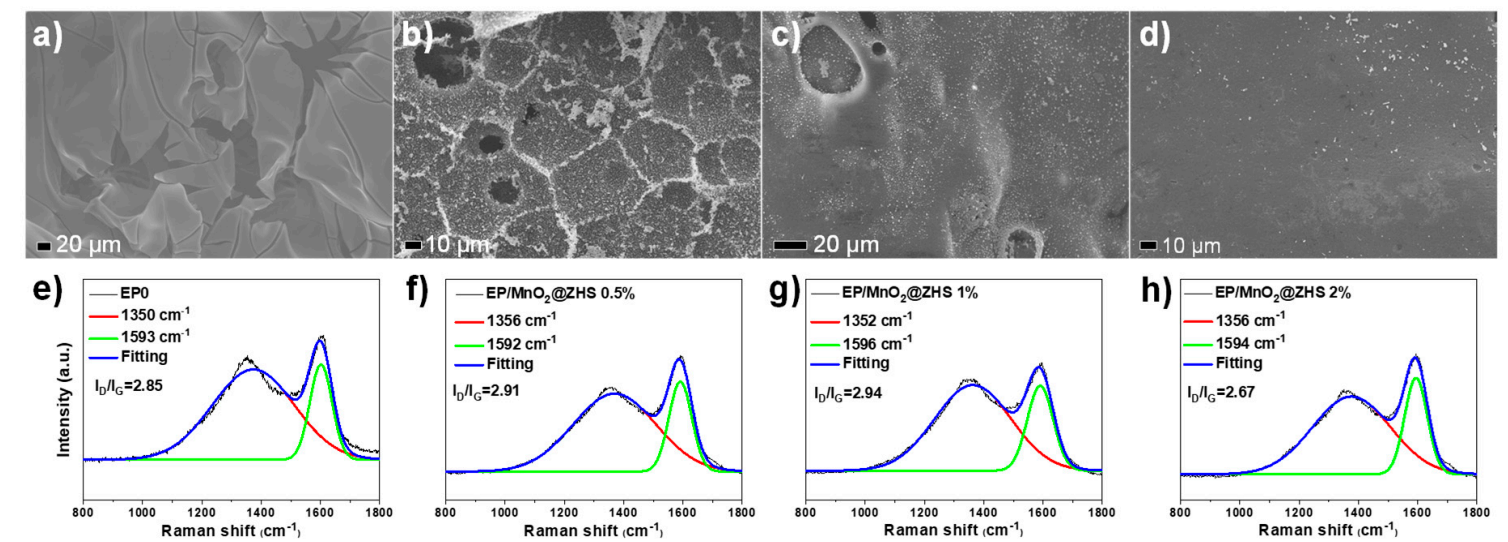

Figure 12. SEM images and Raman spectra of the char residues of $(\mathbf{a}, \mathbf{e})$ pure EP, (b,f) EP/MnO $\mathrm{MZZHS}_{2}$ $0.5 \%,(\mathbf{c}, \mathbf{g}) \mathrm{EP} / \mathrm{MnO}_{2} @ \mathrm{ZHS} 1 \%$, and $(\mathbf{d}, \mathbf{h}) \mathrm{EP} / \mathrm{MnO}_{2} @ \mathrm{ZHS} 2 \%$.

The XPS test was employed to further explore the carbon structure of interior and exterior char residues of pure EP and EP/ $\mathrm{MnO}_{2} @ \mathrm{ZHS} 2 \%$ and their flame retardancy mechanism, as plotted in Figure 13. For all the high-resolution $\mathrm{C}$ 1s spectra, it can be deconvoluted to three characteristic peaks centered at 284.6, 285.6, and $288.3 \mathrm{eV}$, assigned to aliphatic and aromatic species, hydroxyl group and/or ether, and carbonyl groups, respectively. It is generally accepted that the ratios of $C_{o x} / C_{a}\left(C_{o x}\right.$ : oxidized carbon; $\mathrm{C}_{\mathrm{a}}$ : aliphatic and aromatic carbons) are employed to evaluate the thermal oxidative resistance of EP nanocomposites [18]. The lower value of $C_{o x} / C_{a}$ means better thermal oxidative resistance. It is found that the values of $\mathrm{C}_{\mathrm{ox}} / \mathrm{C}_{\mathrm{a}}$ in interior and exterior char residues of pure EP are 0.74 and 0.77, respectively, which are much higher than those of EP/ $\mathrm{MnO}_{2} @ \mathrm{ZHS} 2 \%(0.19$ and 0.41$)$. Therefore, based on these results, it can be well confirmed that $\mathrm{MnO}_{2} @ Z \mathrm{ZHS}$ can promote the char density and graphitization degree of char residues, thereby efficiently enhancing the flame retardancy of the EP matrix. 

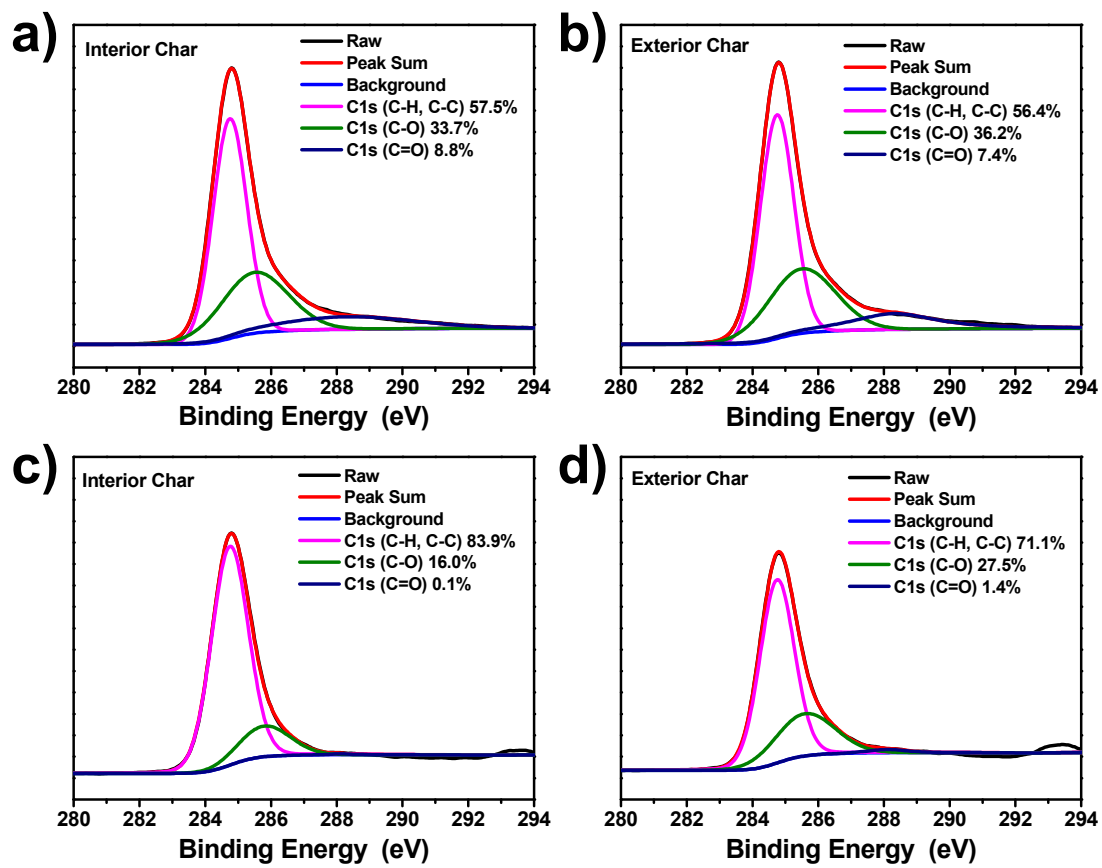

Figure 13. The high-resolution $\mathrm{C} 1 \mathrm{~s}$ spectra of interior and exterior char residues of $(\mathbf{a}, \mathbf{b})$ pure EP and (c,d) EP/ $\mathrm{MnO}_{2} @ \mathrm{ZHS} 2 \%$.

\subsection{Gas-Phase Analysis of Pure EP and EP Nanocomposites}

It is well known that the pyrolysis products of the EP matrix are extremely harmful to the health of humans. Here, TG-IR technique was adopted to study the composition of pyrolysis products during the degradation process of the EP matrix and further investigate the gas-phase mechanism. The FTIR spectra of the pyrolysis products of pristine EP and EP/ $\mathrm{MnO}_{2} @ \mathrm{ZHS} 2 \%$ are presented in Figure 14. It can be concluded that the composition of the pyrolysis products is rarely changed, and the characteristic peaks are strictly ascribed to the functional groups with unambiguous band positions, such as alkane groups mainly for allyl alcohol; hydrocarbons $\left(2820-3120 \mathrm{~m}^{-1}\right)$; aromatic compounds (750, 830, 1460, 1510, and $\left.1610 \mathrm{~cm}^{-1}\right) ; \mathrm{CO}\left(2180 \mathrm{~cm}^{-1}\right) ; \mathrm{CO}_{2}\left(2356 \mathrm{~cm}^{-1}\right)$; and water and/or phenol (ca. $3640-3670 \mathrm{~cm}^{-1}$ ) [26,33].

Figure 15a shows the Gram-Schmidt curves of EP and EP/MnO $\mathrm{MZZHS}_{2} \%$. The incorporation of $\mathrm{MnO}_{2} @ \mathrm{ZHS}$ binary hybrids obviously reduces the absorbance of pyrolysis products, rivalled by that of pure EP. Moreover, Figure 15b,c,f suggest that aromatic compounds and alkane groups are all effectively decreased, implying the reduction of organic gases and improved toxic effluent elimination. Additionally, Figure 15d,e respectively present the absorbance of $\mathrm{CO}$ and $\mathrm{CO}_{2}$, and it can be seen that as the absorbance of $\mathrm{CO}$ decreases, the absorbance of $\mathrm{CO}_{2}$ increases for all the nanocomposites. This could not have an alternative explanation that less pyrolysis gases penetrate the char, making the combustion more ventilated. Therefore, it might very well be a catalysis effect for conversion of $\mathrm{CO}$ into $\mathrm{CO}_{2}$. In summary, TG-IR results demonstrate that $\mathrm{MnO}_{2} @ \mathrm{ZHS}$ binary hybrids can efficiently suppress the production of toxic gases during the degradation of EP nanocomposites, and the addition of binary hybrids can catalyze conversion of $\mathrm{CO}$ into $\mathrm{CO}_{2}$. The mechanism of catalytic conversion of $\mathrm{CO}$ into $\mathrm{CO}_{2}$ is proposed in Figure 16. Combined with the XPS results obtained from Figure 6, it is inferred that the capacity of $\mathrm{Mn}$ to adapt several oxidation states enables it to undergo oxygen reduction reactions, indicating $\mathrm{MnO}_{2}$ nanosheets can act as a reservoir for oxygen, analogous to the previous work [42]. Certainly, toxic gases in real scenarios only contain $\mathrm{CO}$ instead of a wide array of hydrocarbons. Therefore, the catalytic conversion of $\mathrm{CO}$ into $\mathrm{CO}_{2}$ is of great significance. In addition, the increase of $\mathrm{CO}_{2}$ can dilute the oxygen and flammable gases in the air and thereby retard the combustion process. 


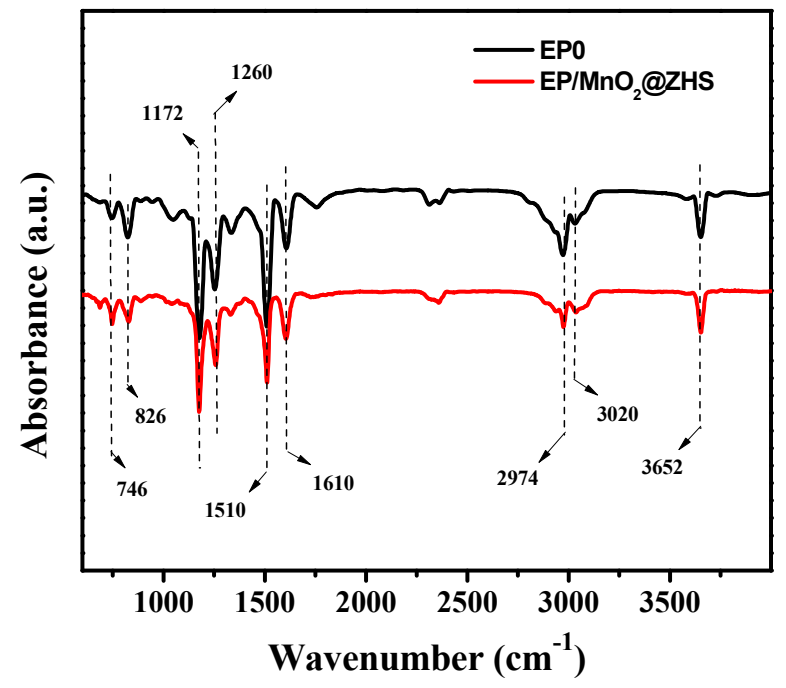

Figure 14. FT-IR spectrum of pyrolysis products of pure EP and EP/ $\mathrm{MnO}_{2} @ \mathrm{ZHS} 2 \%$ composites at the maximum decomposition rate.
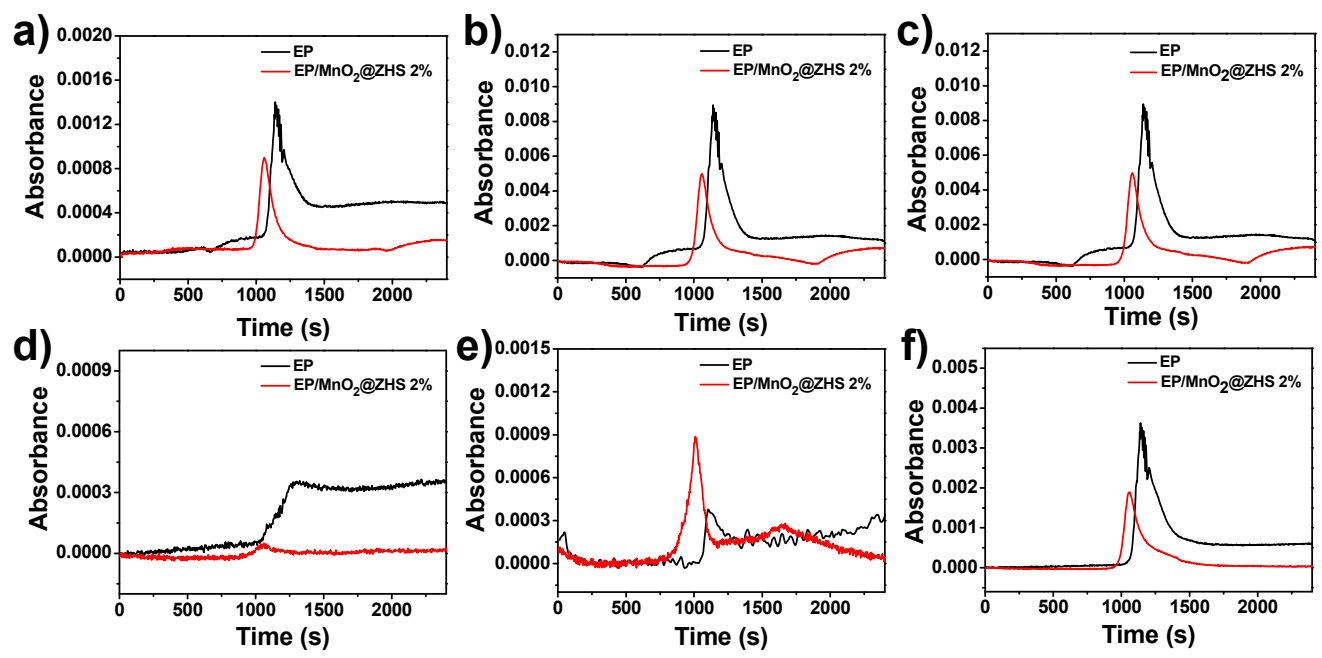

Figure 15. Absorbance of pyrolysis products versus time for EP and its nanocomposites: (a) Gram-Schmidt; (b,c) aromatic compounds located at 1510 and $1610 \mathrm{~cm}^{-1}$; (d) $\mathrm{CO}$; (e) $\mathrm{CO}_{2}$; and (f) hydrocarbons.

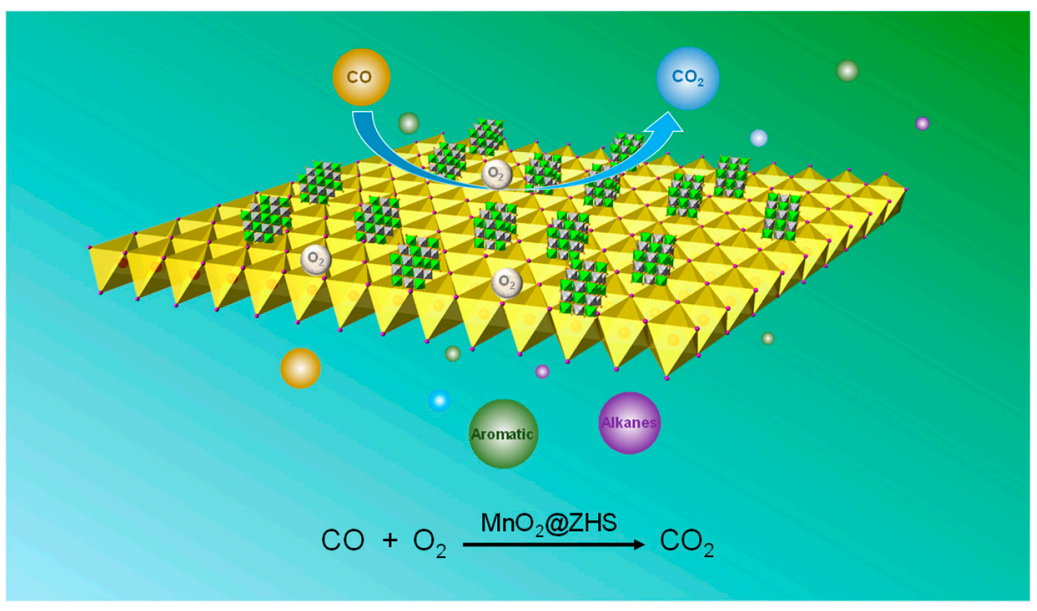

Figure 16. The proposed mechanism of catalytic conversion of $\mathrm{CO}$ into $\mathrm{CO}_{2}$. 


\section{Conclusions}

In this work, a facile method was introduced to synthesize binary hybrids by fabricating ZHS cubes on $\mathrm{MnO}_{2}$ nanosheets with better flame retardancy and toxic effluent elimination of EP. XRD, TEM, and XPS results confirmed the successful synthesis of $\mathrm{MnO}_{2} @ \mathrm{ZHS}$ binary hybrids. Moreover, the SEM and TEM ultrathin images indicated that $\mathrm{MnO}_{2} @ \mathrm{ZHS}$ binary hybrids could achieve strong interfacial interaction with the EP matrix and be well dispersed in nanocomposites. Cone calorimeter test suggested that $\mathrm{MnO}_{2} @ \mathrm{ZHS}$ binary hybrids could effectively suppress the curves of HRR and THR of EP nanocomposites, performing better than $\mathrm{MnO}_{2}$ or ZHS alone. Condensed-phase analysis revealed that $\mathrm{MnO}_{2} @ \mathrm{ZHS}$ binary hybrids could promote the char density and graphitization degree of char residues and thereby successfully retard the permeation of oxygen and flammable gases. Additionally, it was concluded that $\mathrm{MnO}_{2} @ \mathrm{ZHS}$ binary hybrids could efficiently suppress the production of toxic gases during the degradation of EP nanocomposites through the analysis of gas phase.

Author Contributions: L.L. made the investigation and wrote the original draft. W.W. performed the methodology and formal analysis. L.L. and W.W. are the co-first authors. Y.S. performed the project administration and carefully made the investigation. L.F. polished language through the manuscript. L.X. assisted the improvement of language through the manuscript. B.Y. assisted the project administration and supervision. All authors checked the manuscript.

Funding: This research was funded by the Natural Science Foundation of China [Grant Nos. 51803031 and 71804026], and the Natural Science Foundation of Fujian Province, China [Grant No. 2018J05078].

Acknowledgments: The authors sincerely thank Yuan Hu for testing support.

Conflicts of Interest: The authors declare no conflict of interest.

\section{References}

1. Wu, G.M.; Kong, Z.W.; Chen, J.; Huo, S.P.; Liu, G.F. Preparation and properties of waterborne polyurethane/epoxy resin composite coating from anionic terpene-based polyol dispersion. Prog. Org. Coat. 2014, 77, 315-321. [CrossRef]

2. Hadi, P.; Xu, M.; Lin, C.S.; Hui, C.W.; McKay, G. Waste printed circuit board recycling techniques and product utilization. J. Hazard. Mater. 2015, 283, 234-243. [CrossRef] [PubMed]

3. Zhang, H.; Wang, P.; Yang, J. Self-healing epoxy via epoxy-amine chemistry in dual hollow glass bubbles. Compos. Sci. Technol. 2014, 94, 23-29. [CrossRef]

4. Guadagno, L.; Raimondo, M.; Vittoria, V.; Vertuccio, L.; Naddeo, C.; Russo, S.; De Vivo, B.; Lamberti, P.; Spinelli, G.; Tucci, V. Development of epoxy mixtures for application in aeronautics and aerospace. RSC Adv. 2014, 4, 15474-15488. [CrossRef]

5. Vietri, U.; Guadagno, L.; Raimondo, M.; Vertuccio, L.; Lafdi, K. Nanofilled epoxy adhesive for structural aeronautic materials. Compos. Part B-Eng. 2014, 61, 73-83. [CrossRef]

6. Shi, Y.Q.; Yu, B.; Zheng, Y.Y.; Guo, J.; Chen, B.H.; Pan, Z.M.; Hu, Y. A combination of POSS and polyphosphazene for reducing fire hazards of epoxy resin. Polym. Adv. Technol. 2018, 29, 1242-1254. [CrossRef]

7. Watanabe, I.; Sakai, S.I. Environmental release and behavior of brominated flame retardants. Environ. Int. 2003, 29, 665-682. [CrossRef]

8. Czégény, Z.; Jakab, E.; Blazsó, M.; Bhaskar, T.; Sakata, Y. Thermal decomposition of polymer mixtures of PVC, PET and ABS containing brominated flame retardant: Formation of chlorinated and brominated organic compounds. J. Anal. Appl. Pyrol. 2012, 96, 69-77. [CrossRef]

9. Altarawneh, M.; Saeed, A.; Al-Harahsheh, M.; Dlugogorski, B.Z. Thermal decomposition of brominated flame retardants (BFRs): Products and mechanisms. Prog. Energ. Combust. 2019, 70, 212-259. [CrossRef]

10. Altarawneh, M.; Dlugogorski, B.Z. Formation of polybrominated dibenzofurans from polybrominated biphenyls. Chemosphere 2015, 119, 1048-1053. [CrossRef]

11. Blaiszik, B.; Sottos, N.; White, S. Nanocapsules for self-healing materials. Compos. Sci. Technol. 2008, 68, 978-986. [CrossRef] 
12. Noisser, T.; Reichenauer, G.; Husing, N. In Situ Modification of the silica backbone leading to highly porous monolithic hybrid organic-inorganic materials via ambient pressure drying. ACS Appl. Mater. Interfaces 2014, 6, 1025-1029. [CrossRef] [PubMed]

13. Pourhashem, S.; Vaezi, M.R.; Rashidi, A. Investigating the effect of $\mathrm{SiO}_{2}$-graphene oxide hybrid as inorganic nanofiller on corrosion protection properties of epoxy coatings. Surf. Coat. Technol. 2017, 311, 282-294. [CrossRef]

14. Yuan, B.; Hu, Y.; Chen, X.; Shi, Y.; Niu, Y.; Zhang, Y.; He, S.; Dai, H. Dual modification of graphene by polymeric flame retardant and $\mathrm{Ni}(\mathrm{OH})_{2}$ nanosheets for improving flame retardancy of polypropylene. Compos. Part A-Appl. Sci. Manuf. 2017, 100, 106-117. [CrossRef]

15. Shi, Y.; Yu, B.; Duan, L.; Gui, Z.; Wang, B.; Hu, Y.; Yuen, R.K.K. Graphitic carbon nitride/phosphorus-rich aluminum phosphinates hybrids as smoke suppressants and flame retardants for polystyrene. J. Hazard. Mater. 2017, 332, 87-96. [CrossRef] [PubMed]

16. Shi, Y.Q.; Yu, B.; Zheng, Y.Y.; Yang, J.; Duan, Z.P.; Hu, Y. Design of reduced graphene oxide decorated with DOPO-phosphanomidate for enhanced fire safety of epoxy resin. J. Colloid Interf. Sci. 2018, 521, 160-171. [CrossRef] [PubMed]

17. Hapuarachchi, T.D.; Peijs, T. Multiwalled carbon nanotubes and sepiolite nanoclays as flame retardants for polylactide and its natural fibre reinforced composites. Compos. Part A-Appl. Sci. Manuf. 2010, 41, 954-963. [CrossRef]

18. Wang, W.; Pan, H.; Shi, Y.; Pan, Y.; Yang, W.; Liew, K.M.; Song, L.; Hu, Y. Fabrication of LDH nanosheets on $\beta$-FeOOH rods and applications for improving the fire safety of epoxy resin. Compos. Part A-Appl. Sci. Manuf. 2016, 80, 259-269. [CrossRef]

19. Chen, X.; Jiang, Y.; Jiao, C. Smoke suppression properties of ferrite yellow on flame retardant thermoplastic polyurethane based on ammonium polyphosphate. J. Hazard. Mater. 2014, 266, 114-121. [CrossRef] [PubMed]

20. Wang, W.; Pan, H.; Shi, Y.; Yu, B.; Pan, Y.; Liew, K.M.; Song, L.; Hu, Y. Sandwichlike coating consisting of alternating montmorillonite and $\beta-\mathrm{FeOOH}$ for reducing the fire hazard of flexible polyurethane foam. ACS Sustain. Chem. Eng. 2015, 3, 3214-3223. [CrossRef]

21. Pan, H.; Wang, W.; Pan, Y.; Song, L.; Hu, Y.; Liew, K.M. Formation of layer-by-layer assembled titanate nanotubes filled coating on flexible polyurethane foam with improved flame retardant and smoke suppression properties. ACS Appl. Mater. Interfaces 2014, 7, 101-111. [CrossRef] [PubMed]

22. Yu, B.; Shi, Y.; Yuan, B.; Qiu, S.; Xing, W.; Hu, W.; Song, L.; Lo, S.; Hu, Y. Enhanced thermal and flame retardant properties of flame-retardant-wrapped graphene/epoxy resin nanocomposites. J. Mater. Chem. A 2015, 3, 8034-8044. [CrossRef]

23. Wang, W.; Kan, Y.; Pan, H.; Pan, Y.; Li, B.; Liew, K.M.; Hu, Y. Phosphorylated cellulose applied for the exfoliation of LDH: An advanced reinforcement for polyvinyl alcohol. Compos. Part A-Appl. Sci. Manuf. 2017, 94, 170-177. [CrossRef]

24. Zhou, K.; Gao, R.; Qian, X. Self-assembly of exfoliated molybdenum disulfide $\left(\mathrm{MoS}_{2}\right)$ nanosheets and layered double hydroxide (LDH): Towards reducing fire hazards of epoxy. J. Hazard. Mater. 2017, 338, 343-355. [CrossRef] [PubMed]

25. Wang, W.; Kan, Y.; Liu, J.; Liew, K.M.; Liu, L.; Hu, Y. Self-assembly of zinc hydroxystannate on amorphous hydrous $\mathrm{TiO}_{2}$ solid sphere for enhancing fire safety of epoxy resin. J. Hazard. Mater. 2017, 340, $263-271$. [CrossRef] [PubMed]

26. Wang, W.; Kan, Y.; Pan, Y.; Yuan, Y.; Liew, K.M.; Hu, Y. Urchinlike shells of $\mathrm{TiO}_{2}$ hollow spheres for improving the fire safety of epoxy resin. Ind. Eng. Chem. Res. 2017, 56, 1341-1348. [CrossRef]

27. Gu, H.; Guo, J.; He, Q.; Tadakamalla, S.; Zhang, X.; Yan, X.; Huang, Y.; Colorado, H.A.; Wei, S.; Guo, Z. Flame-retardant epoxy resin nanocomposites reinforced with polyaniline-stabilized silica nanoparticles. Ind. Eng. Chem. Res. 2013, 52, 7718-7728. [CrossRef]

28. Ran, S.; Guo, Z.; Han, L.; Fang, Z. Effect of a lewis acid catalyst on the performance of HDPE/BFR/GNPs composites. Ind. Eng. Chem. Res. 2014, 53, 4711-4717. [CrossRef]

29. Li, L.P.; Zheng, T.; Xu, L.N.; Li, Z.; Sun, L.D.; Nie, Z.X.; Bai, Y.; Liu, H.W. $\mathrm{SnO}_{2}-\mathrm{ZnSn}(\mathrm{OH})_{6}$ : A novel binary affinity probe for global phosphopeptide detection. Chem. Commun. 2013, 49, 1762-1764. [CrossRef]

30. Carosio, F.; Alongi, J.; Malucelli, G. Layer by layer ammonium polyphosphate-based coatings for flame retardancy of polyester-cotton blends. Carbohydr. Polym. 2012, 88, 1460-1469. [CrossRef] 
31. Carosio, F.; Di Blasio, A.; Cuttica, F.; Alongi, J.; Frache, A.; Malucelli, G. Flame retardancy of polyester fabrics treated by spray-assisted layer-by-layer silica architectures. Ind. Eng. Chem. Res. 2013, 52, 9544-9550. [CrossRef]

32. Wang, W.; Pan, Y.; Pan, H.; Yang, W.; Liew, K.M.; Song, L.; Hu, Y. Synthesis and characterization of $\mathrm{MnO}_{2}$ nanosheets based multilayer coating and applications as a flame retardant for flexible polyurethane foam. Compos. Sci. Technol. 2016, 123, 212-221. [CrossRef]

33. Wang, W.; Kan, Y.; Yu, B.; Pan, Y.; Liew, K.M.; Song, L.; Hu, Y. Synthesis of $\mathrm{MnO}_{2}$ nanoparticles with different morphologies and application for improving the fire safety of epoxy. Compos. Part A-Appl. Sci. Manuf. 2017, 95, 173-182. [CrossRef]

34. Sinha, A.K.; Pradhan, M.; Pal, T. Morphological evolution of two-dimensional $\mathrm{MnO}_{2}$ nanosheets and their shape transformation to one-dimensional ultralong $\mathrm{MnO}_{2}$ nanowires for robust catalytic activity. J. Phys. Chem. C 2013, 117, 23976-23986. [CrossRef]

35. Wrobel, G.; Piech, M.; Dardona, S.; Ding, Y.; Gao, P.X. Seedless synthesis and thermal decomposition of single crystalline zinc hydroxystannate cubes. Cryst. Growth Des. 2009, 9, 4456-4460. [CrossRef]

36. Ma, Z.; Shao, G.; Fan, Y.; Wang, G.; Song, J.; Shen, D. Construction of hierarchical $\alpha-\mathrm{MnO}_{2}$ nanowires@ ultrathin $\delta-\mathrm{MnO}_{2}$ nanosheets core-shell nanostructure with excellent cycling stability for high-power asymmetric supercapacitor electrodes. ACS Appl. Mater. Interfaces 2016, 8, 9050-9058. [CrossRef] [PubMed]

37. Fu, X.; Huang, D.; Qin, Y.; Li, L.; Jiang, X.; Chen, S. Effects of preparation method on the microstructure and photocatalytic performance of $\mathrm{ZnSn}(\mathrm{OH})_{6}$. Appl. Catal. B-Environ. 2014, 148, 532-542. [CrossRef]

38. Luo, P.; Zhang, H.; Liu, L.; Fang, L.; Wang, Y. Sandwich-like nanostructure of amorphous $\mathrm{ZnSnO}_{3}$ encapsulated in carbon nanosheets for enhanced lithium storage. Electrochim. Acta 2016, 219, 734-741. [CrossRef]

39. Singu, B.S.; Hong, S.E.; Yoon, K.R. Ultra-thin and ultra-long $\alpha-\mathrm{MnO}_{2}$ nanowires for pseudocapacitor material. J. Solid State Electr. 2017, 21, 3215-3220. [CrossRef]

40. Li, D.; Li, W.; Deng, Y.; Wu, X.; Han, N.; Chen, Y. Effective Ti doping of $\delta-\mathrm{MnO}_{2}$ via anion route for highly active catalytic combustion of benzene. J. Phys. Chem. C 2016, 120, 10275-10282. [CrossRef]

41. Wang, W.; Pan, H.; Yu, B.; Pan, Y.; Song, L.; Liew, K.M.; Hu, Y. Fabrication of carbon black coated flexible polyurethane foam for significantly improved fire safety. RSC Adv. 2015, 5, 55870-55878. [CrossRef]

42. Miran, H.A.; Altarawneh, M.; Jiang, Z.T.; Oskierski, H.; Almatarneh, M.; Dlugogorski, B.Z. Decomposition of selected chlorinated volatile organic compounds by ceria $\left(\mathrm{CeO}_{2}\right)$. Catal. Sci. Technol. 2017, 7, 3902-3919. [CrossRef]

(C) 2019 by the authors. Licensee MDPI, Basel, Switzerland. This article is an open access article distributed under the terms and conditions of the Creative Commons Attribution (CC BY) license (http:/ / creativecommons.org/licenses/by/4.0/). 